\title{
Identification of Acoustic Characteristic Parameters and Improvement of Sound Absorption Performance for Porous Metal
}

\author{
Xiaocui Yang ${ }^{1}$, Xinmin Shen ${ }^{2,3, *}$, Haiqin Duan ${ }^{2}$, Xiaonan Zhang ${ }^{2}$ and Qin Yin ${ }^{2}$ \\ 1 Engineering Training Center, Nanjing Institute of Industry Technology, No. 1 north Yangshan road, \\ Nanjing 210023, China; 2019101052@niit.edu.cn \\ 2 Department of Mechanical Engineering, College of Field Engineering, Army Engineering University, No. 1 \\ Haifu Street, Nanjing 210007, China; dhq1135168523@163.com (H.D.); zxn8206@163.com (X.Z.); \\ dafengyinqin@126.com (Q.Y.) \\ 3 State Key Laboratory of Ultra-precision Machining Technology, Department of Industrial and Systems \\ Engineering, The Hong Kong Polytechnic University, Kowloon 999077, Hong Kong, China \\ * Correspondence: shenxmjfilgdx2014@163.com; Tel.: +86-025-8082-1451
}

Received: 26 January 2020; Accepted: 2 March 2020; Published: 3 March 2020

\begin{abstract}
Porous metal is widely used in the fields of sound absorption and noise reduction, and it is a critical procedure to identify acoustic characteristic parameters and to improve sound absorption performances. Based on the constructed theoretical sound absorption model and experimental data, acoustic characteristic parameters of the porous metal were identified through the cuckoo search identification algorithm, and their reliabilities were certified through comparing with these labeled parameters and further experimental validation. By adding the microperforated metal panel in front of the porous metal, a composite sound-absorbing structure was formed, which aimed to improve the sound absorption performance of the original porous metal by optimizing the parameters. Finite element simulation and a standing wave tube measurement were conducted to validate the effectiveness and practicability of the optimal composite sound-absorbing structure. Consistencies among theoretical predictions, simulation results, and experimental data proved the effectiveness of the identification and optimization method. When the target frequency ranges were $100-1000 \mathrm{~Hz}$, $100-2000 \mathrm{~Hz}, 100-3000 \mathrm{~Hz}$, and 100-4000 Hz. Actual average sound absorption coefficients of the optimal composite structures were $0.5154,0.6369,0.6770$, and 0.7378 , respectively, which exhibited the obvious improvements with a tiny increase in the occupied space and a small addition in weight.
\end{abstract}

Keywords: porous metal; acoustic characteristic parameter; sound absorption performance; cuckoo search algorithm; identification and optimization; microperforated metal panel

\section{Introduction}

The sound absorption and noise reduction are mainly applications of the porous metal because it has the advantages of excellent absorption performance, a wide absorption band, outstanding flame resistance, extraordinary light weight, satisfactory cost-effective ratio, and so on [1-5]. Hakamada et al. [1] had produced the porous aluminum with a density of $0.27 \mathrm{~g} / \mathrm{cm}^{3}$ by the spacer method, and a sound absorption coefficient near unity was achieved by inserting an air gap back to the sample. The porous copper was prepared by Ru et al. [2] through a novel rosin curing and foaming method, and influences of resin content on the micropore structure and its sound absorption were investigated. The nickel-based superalloy open-cell foam with the controllable porosity (92-98\%) and cell size (300-900 $\mu \mathrm{m})$ was prepared by Zhai et al. [3] the through template replication process, which achieved sound absorption coefficient $>0.9$ at the frequency $>1500 \mathrm{~Hz}$ with a thickness of $50 \mathrm{~mm}$. 
Geometrical and dimensional optimization of the sound-absorbing porous copper with cavity was conducted by Yang et al. [4], which obtained a sound absorption coefficient $>0.7$ at the frequency range $2000-5000 \mathrm{~Hz}$ with a thickness of $28.8 \mathrm{~mm}$. Liu et al. [5] investigated the sound absorption performance of the highly porous titanium foams, and it was concluded that the main sound absorption mechanism was the interference silencing due to the surface reflection at low-frequency range and viscous dissipation at a high-frequency range. Therefore, the porous metal is considered as one of the research focuses on the fields of sound absorption and noise reduction.

Besides these common porous sound-absorbing materials [1-5], some novel sound absorbers have already been developed from the standard porous metal [6-15]. Bai et al. [6] had attempted to improve sound absorption efficiency of the porous metal by compression, and further promote the sound absorption performance by microperforation [7]. The gradient compressed porous metal had been proposed by Yang et al. [8], which obtained the average sound absorption coefficient of 0.6033 in the $100-6000 \mathrm{~Hz}$ range with a total thickness of $11 \mathrm{~mm}$. The thin acoustic absorber of multilayer compressed porous metal with rear cavity was investigated by Shen et al. [9], and its average sound absorption coefficient of the optimal four-layer compressed porous metal with the total thickness of $5 \mathrm{~mm}$ reached $0.5105 \mathrm{in}$ the 100-6000 Hz. Otaru et al. [10] proposed and optimized the porous metal with a bottleneck-type structure, which obtained the the optimal sound absorption performance when its porosity was 0.68 . Meanwhile, the composite structures consisted of porous metal and the other sound-absorbing materials are treated as an effective method to develop the practical acoustic absorbers for some normal or special applications [11-15]. Lu et al. [11] had investigated influences of the microperforated panel combination on the sound absorption performance of the nickel foam, which indicated that the sound absorption coefficient was controlled by adjusting the thickness of the composite layer and location of the perforated panel. High-performance aluminum foam sandwich was prepared by Peng et al. [12] through the friction stir welding, which could obtain outstanding sound absorption property. Shen et al. [13] had fabricated the low-frequency sound absorber by the combination of porous metal and microperforated panel, which could achieve the average sound absorption coefficients of 0.6296 and 0.7359 in the $100-1800 \mathrm{~Hz}$ with limited total thicknesses of 30 $\mathrm{mm}$ and $50 \mathrm{~mm}$, respectively. A simple two-dimensional microstructural model of the perforated closed-cell metallic foam was presented by Chevillotte et al. [14,15], which attempted to understand how perforation interacted with the closed-cell foam microstructure and how it modified the sound absorption of the foam. Therefore, porous metal and its derivatives are widely utilized in sound absorption and attract worldwide research enthusiasm.

Normally, no matter for the common porous metal or for composite sound-absorbing structure, the structural parameters must be optimized to achieve the satisfactory sound absorption performance under certain constraint conditions [16-21]. Acoustic topology optimization of porous material distribution based on the adjoint variable fast multipole boundary element method was conducted by Zhao et al. [16], and its ability to handle the large-scale problems was validated through numerical examples of acoustic scattering over a single cylinder and multiple cylinders. Zhu et al. [17] investigated the effects of gradient pore structure on the sound absorption performance of the metal fiber porous material, and the sound absorption coefficient was improved due to repeated reflection of the sound wave in the porous media between gradient interfaces. A ten-layer gradient compressed porous metal with a thickness of $20 \mathrm{~mm}$ was optimized to obtain an excellent sound absorption performance by Yang et al. [18], and its average sound absorption coefficients could reach $0.3325,0.5412,0.7461$, and 0.7617 when the frequency ranges were $100-1000 \mathrm{~Hz}, 100-2000 \mathrm{~Hz}, 100-4000 \mathrm{~Hz}$, and 100-6000 Hz, respectively. Takezawa et al. [19] proposed new topology optimization by the solid isotropic material with the penalization method for optimizing a sound-absorbing material layout, which obtained the appropriate solutions and generated the optimal result for each selected sample. Parametric optimization and analysis of a metallic porous material were conducted by Barbosa and Lenzi [20], who aimed to reduce the gas pulsation noise in the household refrigerators. Park et al. [21] carried out multistage numerical analysis of the polyurethane foam, and it could be proved that reduction of the 
mean cell diameter could enhance acoustic damping efficiency in low-frequency ranges. Therefore, parameter optimization is the critical step to develop the novel sound absorber, and it is extremely important to obtain acoustic characteristic parameters of the porous metal.

According to the classical Johnson-Champoux-Allard model [22-24], major acoustic characteristic parameters for the porous material were porosity and static flow resistivity. Although the porosity is easy to obtain, it is difficult to accurately measure the static flow resistivity [3,8,25-27]. Therefore, identification of the acoustic characteristic parameters, which included the porosity and static flow resistivity, were conducted through the cuckoo search algorithm $[28,29]$ based on the experimental data of the sound absorption coefficient of the porous metal in this study. Afterward, the sound absorption performance of the porous metal was improved through adding the microperforated metal panel in front of it to form a composite sound-absorbing structure. After that, the theoretical sound absorption model of the composite structure was constructed by the transfer matrix method [9,13,30-32]. Then, parameters of the composite structures were optimized by the cuckoo search algorithm $[8,18,28,29]$ to achieve maximum average sound absorption coefficient in a certain frequency range. Moreover, the effectiveness and practicability of the optimal composite sound-absorbing structures were verified through the finite element simulation in the virtual acoustic laboratory [33-35]. Finally, accuracy and reliability of theoretical sound absorption model, cuckoo search identification and optimization algorithm, and finite element simulation method were testified by the experimental validation, and experimental data of sound absorption coefficients of the porous metal and those of the composite sound-absorbing structures were obtained by the standing wave tube measurement [36-38]. By this method, identification of acoustic characteristic parameters and improvement of the sound absorption performance for porous metal were conducted, which aimed to promote its practical application.

\section{Identification and Verification}

Morphologies of the porous copper used in this research are shown in Figure 1, which was purchased from the Yiyang Foammetal New Material Co., Ltd., Yiyang, Hunan, China. According to the Johnson-Champoux-Allard model [22-24], theoretical sound absorption coefficients of the porous metal with a certain thickness could be calculated by confirming its acoustic characteristic parameters. Therefore, the acoustic characteristic parameters, including the porosity and static flow resistivity, would be inversed based on the experimental data of the sound absorption coefficient of the porous metal through the cuckoo search algorithm $[28,29]$. Afterward, the effectiveness and accuracy of this identification method were verified.

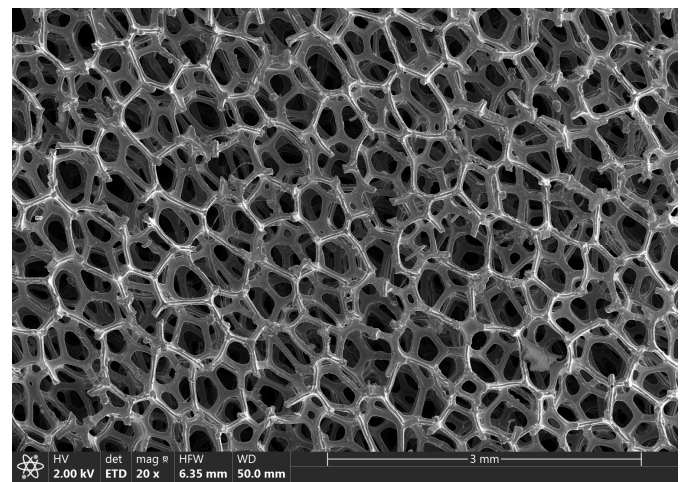

(a)

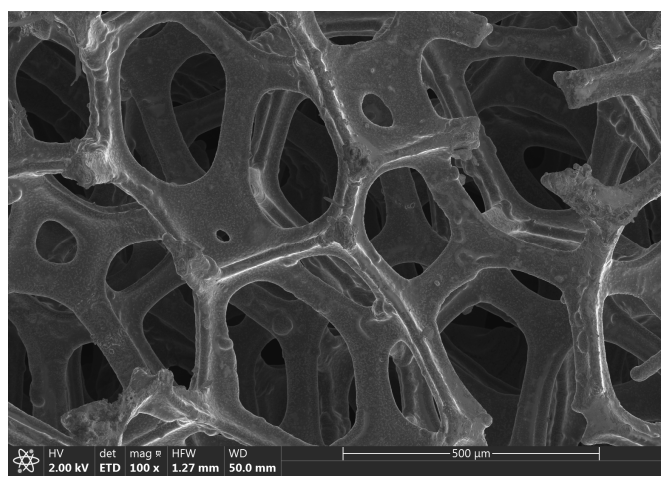

(b)

Figure 1. Structural morphologies of the porous metal obtained by the scanning electron microscope (a) with a low magnification of $20 \times$ and (b) with a high magnification of $100 \times$. 


\subsection{Theoretical Model of Sound Absorption Coefficient}

The sound absorption coefficient of the porous metal $\alpha_{p}$ is obtained by calculating its transfer matrix $T_{p}$ according to the transfer matrix method [9,13,30-32], as shown in Equation (1). Here, $T_{p 11}$ and $T_{p 21}$ are two components of the transfer matrix $T_{p}$ of the porous metal, which can be calculated by Equation (2); $\rho$ is density of the air with normal atmospheric temperature, $1.21 \mathrm{~kg} / \mathrm{m}^{3} ; c$ is the acoustic velocity in air, $340 \mathrm{~m} / \mathrm{s} ; \operatorname{Re}()$ and $\operatorname{Im}()$ represent the real part and imaginary part of the complex number, respectively.

$$
\begin{gathered}
\alpha_{p}=\frac{4 \times \operatorname{Re}\left(\frac{T_{p 11}}{T_{p 21}} \times \frac{1}{\rho c}\right)}{\left[1+\operatorname{Re}\left(\frac{T_{p 11}}{T_{p 21}} \times \frac{1}{\rho c}\right)\right]^{2}+\left[\operatorname{Im}\left(\frac{T_{p 11}}{T_{p 21}} \times \frac{1}{\rho c}\right)\right]^{2}} \\
T_{p}=\left[\begin{array}{cc}
T_{p 11} & T_{p 12} \\
T_{p 21} & T_{p 22}
\end{array}\right]=\left[\begin{array}{cc}
\cos \left(k_{p} d_{p}\right) & j Z_{p} \sin \left(k_{p} d_{p}\right) \\
j Z_{p}^{-1} \sin \left(k_{p} d_{p}\right) & \cos \left(k_{p} d_{p}\right)
\end{array}\right]
\end{gathered}
$$

For the porous metal in Equation (2), $k_{p}$ is the wave number in it, which can be obtained by Equation (3); $Z_{p}$ is its characteristic impedance, which can be achieved by Equation (4); $d_{p}$ is its thickness, which can be measured by the Vernier caliper; $j$ is a symbol of the imaginary number, $j^{2}=-1[22-24]$.

$$
\begin{gathered}
k_{p}=\omega \sqrt{\frac{\rho(\omega)}{K(\omega)}} \\
Z_{p}=\sqrt{\rho(\omega) \times K(\omega)}
\end{gathered}
$$

In Equations (3) and (4), $\omega$ is angular frequency of the sound wave, which is obtained by Equation (5); $\rho(\omega)$ is complex effective density of the porous metal, which can be achieved by Equation (6); $K(\omega)$ is complex effective bulk modulus of the porous metal, which can be calculated by Equation (7) [22-24].

$$
\begin{gathered}
\omega=2 \pi f \quad f \in\left[f_{\min }, f_{\max }\right] \\
\rho(\omega)=\rho\left[1+\left(3^{2}+\frac{4 \omega \rho}{\sigma \phi}\right)^{-0.5}-j \frac{\sigma \phi}{\omega \rho}\left(1+\frac{\omega \rho}{4 \sigma \phi}\right)^{0.5}\right] \\
K(\omega)=\gamma P_{0}\left[\gamma-(\gamma-1)\left(1-N_{u}\left(j \frac{8 \omega \rho P_{r}}{\sigma \phi}+N_{u}\right)^{-1}\right)\right]^{-1}
\end{gathered}
$$

In Equation (5), $f$ is the sound frequency, and its range can be symbolled as $\left[f_{\min }, f_{\max }\right]$. In Equations (6) and (7), $\rho$ is still density of the air with the normal atmospheric temperature, $1.21 \mathrm{~kg} / \mathrm{m}^{3}$; $\sigma$ is static flow resistivity of the porous metal; $\phi$ is porosity of the porous metal; $\gamma$ is specific heat ratio of the air with the normal atmospheric temperature, $1.40 ; P_{0}$ is static pressure of the air with normal atmospheric temperature, $1.013 \times 10^{5} \mathrm{~Pa} ; N_{u}$ is the Nusselt number, 4.36; $P_{r}$ is the Prandtl number, $0.71 ; j$ is the still symbol of the imaginary number, $j^{2}=-1$ [22-24].

It could be judged from Equations (1)-(7) that the sound absorption coefficient $\alpha_{p}$ of the porous metal was determined by the acoustic characteristic parameters of static flow resistivity $\sigma$ and porosity $\phi$ for the certain thickness $d_{p}$ and the certain frequency $f$. Therefore, the acoustic characteristic parameters $\sigma$ and $\phi$ would be inversed based on the theoretical model by a series of experimental data, which consisted of the sound absorption coefficient $\alpha_{p}$, thickness $d_{p}$, and frequency $f$.

\subsection{Standing Wave Tube Measurement}

Sound absorption coefficients of the porous metal with thicknesses of $15 \mathrm{~mm}, 20 \mathrm{~mm}, 25 \mathrm{~mm}$, and $30 \mathrm{~mm}$, respectively, were obtained by the AWA6128A detector (Hangzhou Aihua Instruments Co., Ltd., Hangzhou, China) according to standing wave tube measurement [36-38], and schematic diagram of 
the measurement is shown in Figure 2. The detected porous metal sample was installed in the sample fixer, and its back surface was supported by the rigid wall of the sample holder. The incident sound wave was generated from the loudspeaker box and input into a standing wave tube, and its frequency was controlled by software on the computer. The reflected sound wave was detected through the acoustic probe on the pulley, and the peak sound level $L_{\max }$ and the corresponding valley sound level $L_{\text {min }}$ for a certain frequency $f$ could be obtained by moving the pulley on the slideway. According to the testing principle of the utilized AWA6128A detector, the corresponding sound absorption coefficient could be calculated through Equation (8) [4]. The investigated frequencies for each sample were in the $100-6000 \mathrm{~Hz}$ range with an interval of $50 \mathrm{~Hz}$, which indicated that $476(119 \times 4=476)$ series of experimental data were obtained for further identification. In order to reduce the measuring error in the testing program, each porous metal sample was tested 10 times, and the final experimental data was the average value of these 10 testing data. It had been proved by Duan et al. [39] that undulation of the experimental data could be kept within $\pm 0.2 \%$ among the 10 testing data, which certified veracity and repeatability of this experimental measurement.

$$
\alpha_{e}(f)=\frac{4 \times 10^{\frac{L_{\max }-L_{\min }}{20}}}{\left(1+10^{\frac{L_{\max }-L_{\min }}{20}}\right)^{2}}
$$

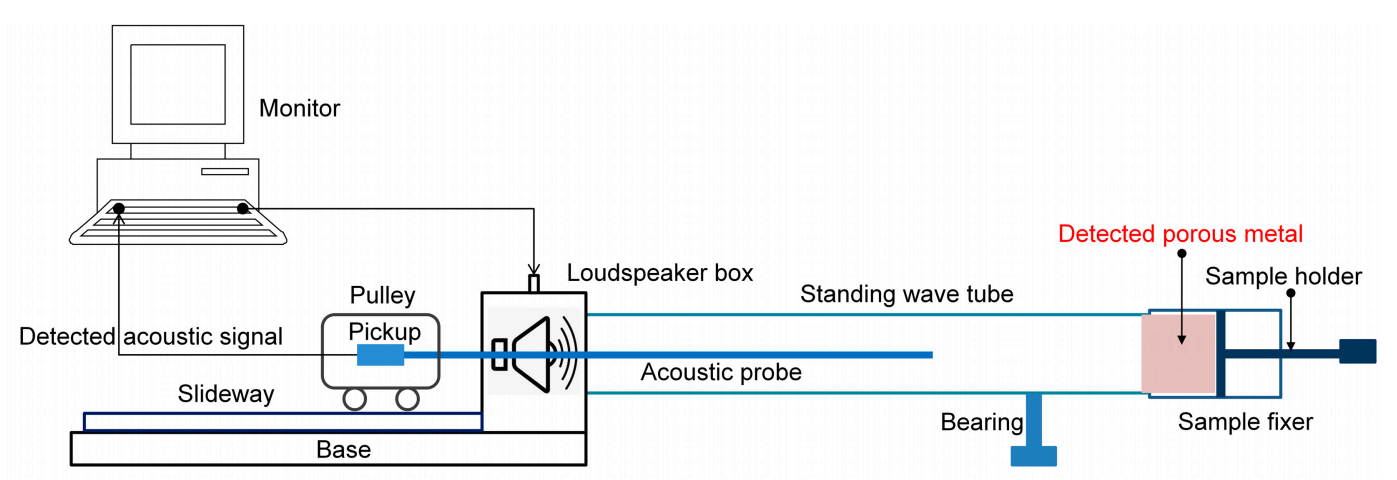

Figure 2. Schematic diagram of the standing wave tube measurement by AWA6128A detector.

\subsection{Identification of Acoustic Characteristic Parameters}

Acoustic characteristic parameters $\sigma$ and $\phi$ of the porous metal in this study were constant waiting to be determined, which could be identified through the cuckoo search algorithm [28,29] according to the 476 series of experimental data of the sound absorption coefficient $\alpha$, thickness $d_{p}$, and frequency $f$. The flow chart of the identification of the acoustic characteristic parameters is shown in Figure 3. According to the definition of the porosity, it could be found that its reasonable range was $(0,1)$, as shown in Equation (9). Meanwhile, normal static flow resistivity of the porous metal was $[5000,50000]$, so the selected range was $[1000,100000]$ in this research, as shown in Equation (10). Moreover, the optimization target was to minimize the residual error between the experimental data and the theoretical prediction of the sound absorption coefficient of the porous metal, as shown in Equation (11). By confirmation of the constraint conditions and optimization target, identification of the acoustic characteristic parameters was realized.

$$
\begin{gathered}
1>\phi>0 \\
1 \times 10^{5} \mathrm{~Pa} \cdot \mathrm{s} \cdot \mathrm{m}^{-2} \geq \sigma \geq 1 \times 10^{3} \mathrm{~Pa} \cdot \mathrm{s} \cdot \mathrm{m}^{-2} \\
\min \left(\alpha_{e}\left(f, d_{p}\right)-\alpha_{t}\left(f, d_{p}\right)\right) \quad f \in[100,6000], d_{p}=[15,20,25,30]
\end{gathered}
$$




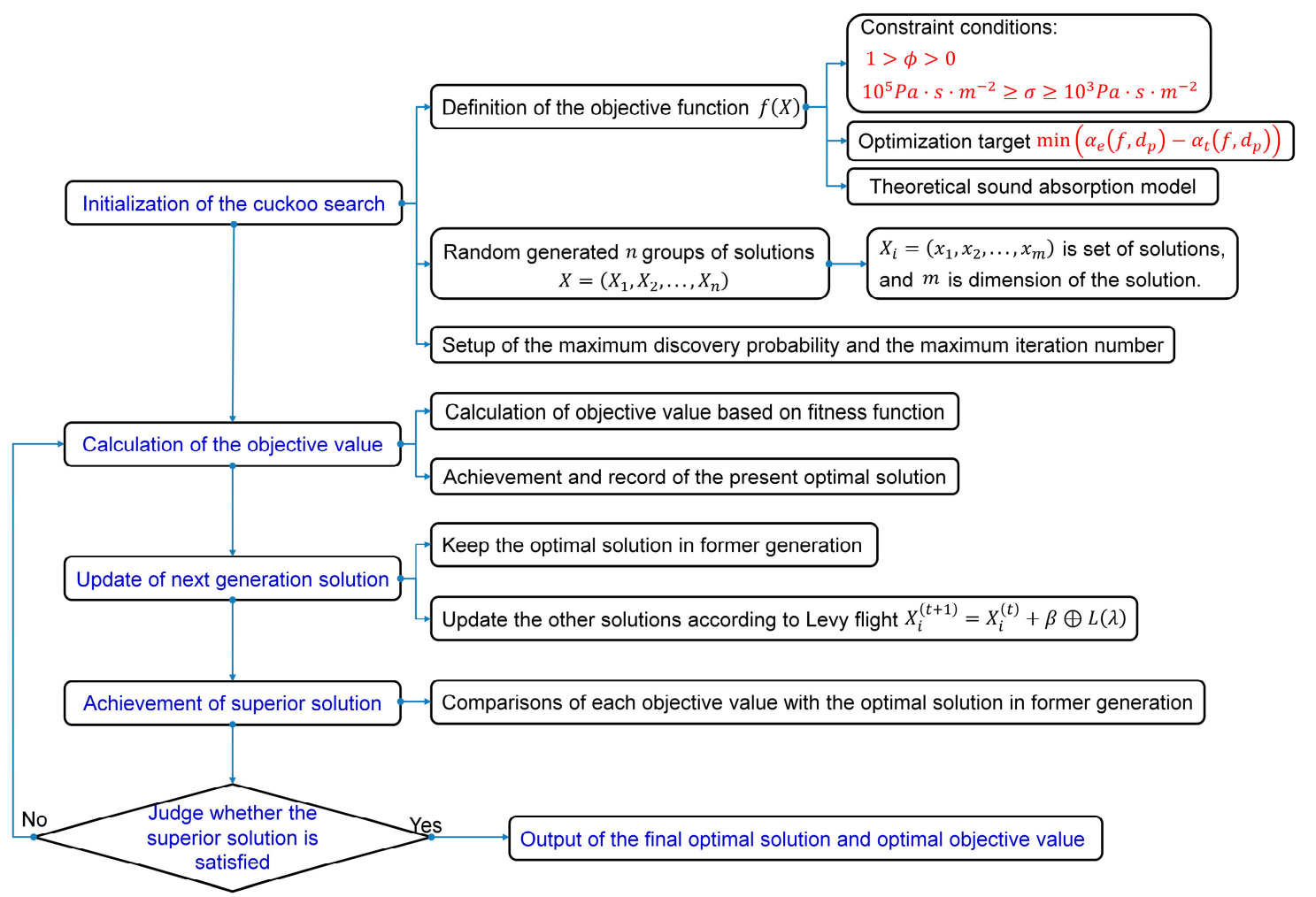

Figure 3. Flow chart of identification of the acoustic characteristic parameters through the cuckoo search algorithm.

In Equations (6) and (7), it was interesting to note that the static flow resistivity $\sigma$ and porosity $\phi$ always appeared in the form of a product, which indicated that optimal solutions of the acoustic characteristic parameters were a group instead of only one. Thus, the product of the static flow resistivity and porosity was treated as one parameter, and the optimization result of the cuckoo search identification algorithm is shown in Figure 4. Along with the increase of the function evaluation times from 0 to 2000, it could be observed that the identified product of the acoustic characteristic parameter and the residual error gradually stabilized. The optimal product of static flow resistivity $\sigma$ and porosity $\phi$ obtained by the cuckoo search algorithm was 6982.5, and the optional acoustic characteristic parameters are shown in Figure 5. With ranges of the porosity from 0.1 to 1 , the corresponding static flow resistivity $\sigma$ decreased from $69,825 \mathrm{~Pa} \cdot \mathrm{s} \cdot \mathrm{m}^{-2}$ to $6982.5 \mathrm{~Pa} \cdot \mathrm{s} \cdot \mathrm{m}^{-2}$. Though the accurate static flow resistivity and porosity were not confirmed by the cuckoo search identification algorithm, the obtained optimal product of the two structural parameters was enough for the further improvement of the sound absorption performance of the porous metal. Moreover, non-uniqueness of the optional acoustic characteristic parameters indicated that different porous metal could exhibit the same sound absorption performance as long as the product of the static flow resistivity and the porosity were equal. Therefore, the excellent sound absorbers with unique properties, such as high fire retardancy, strong corrosion resistance, outstanding light transparency, and so on, could be developed through choosing different kinds of porous material. Furthermore, as mentioned above, the test of porosity of the porous metal was easy to realize relative to that of its static flow resistivity. Therefore, the porosity of the porous metal utilized in this study was measured through the drainage method [40], and its actual value was 0.9136 . The static flow resistivity could be calculated, $7642.8 \mathrm{~Pa} \cdot \mathrm{s} \cdot \mathrm{m}^{-2}$. The labeled porosity and static flow resistivity provided by the supplier were 0.9 and $7680 \mathrm{~Pa} \cdot \mathrm{s} \cdot \mathrm{m}^{-2}$, respectively, which could validate the effectiveness and accuracy of the cuckoo search identification algorithm. 


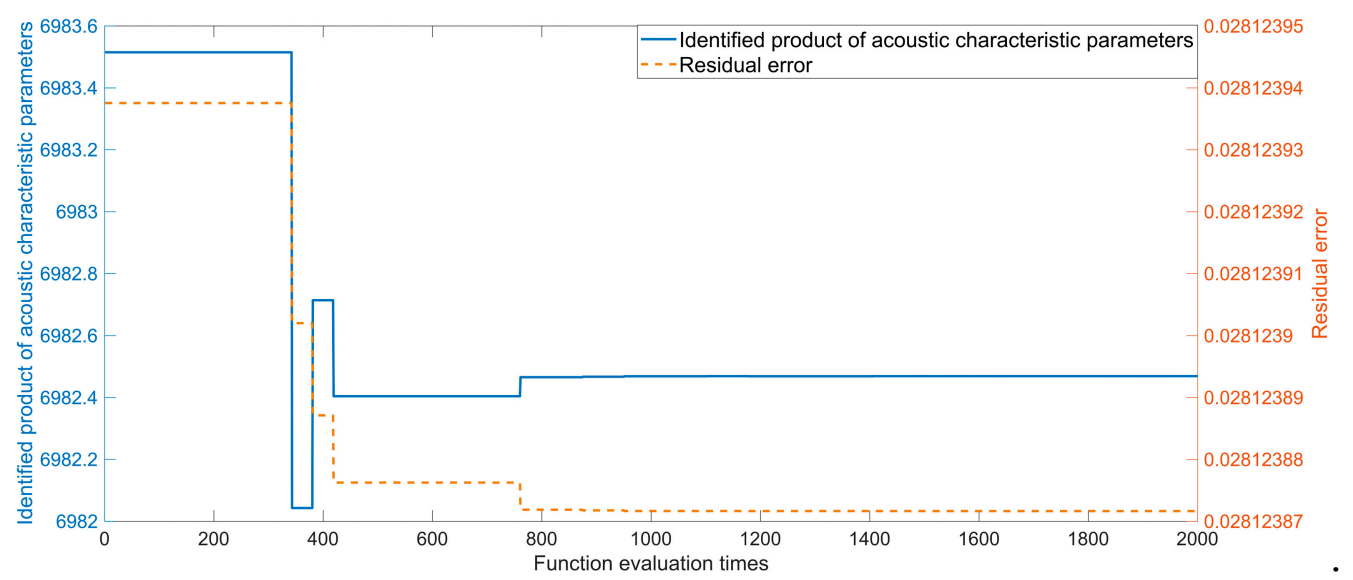

Figure 4. Optimization results of the cuckoo search identification algorithm.

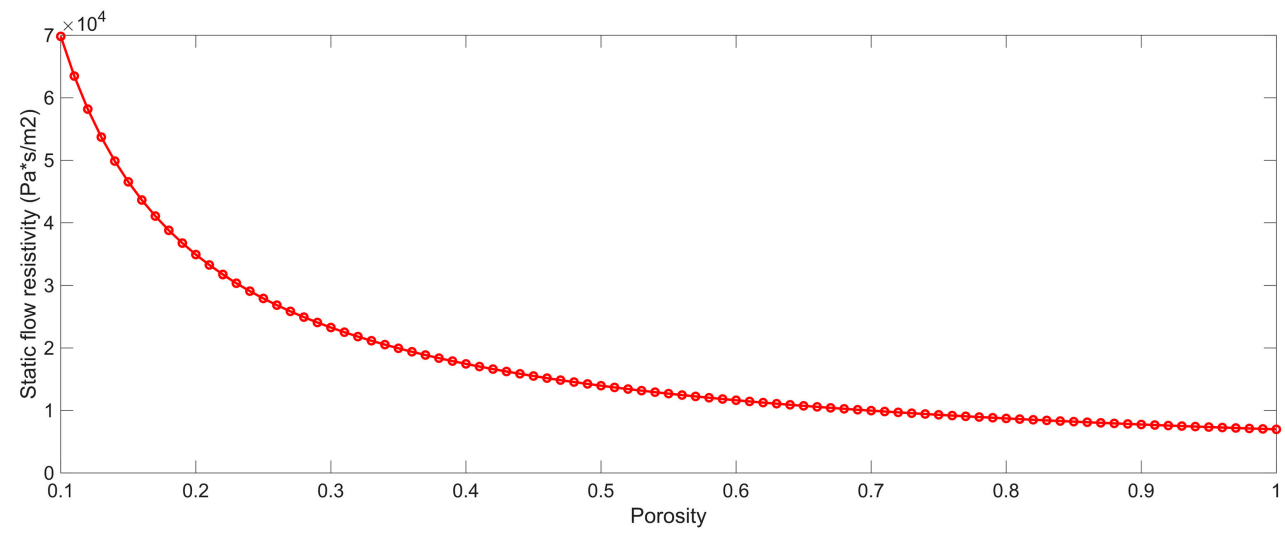

Figure 5. Distribution of the optional acoustic characteristic parameters of static flow resistivity and porosity.

\subsection{Verification and Evaluation}

By putting the identified acoustic characteristic parameters into the theoretical model in Equations (1)-(7), the theoretical sound absorption coefficients of the porous metal with different thicknesses could be obtained, and they were compared with the experimental data, as shown in Figure 6. It could be found that the consistency between theoretical prediction and experimental data was excellent. The total departure of the regressive average value $R^{2}$ was used to quantitatively express the deviation between the theoretical predictions and experimental data, as shown in Equation (12) [6,41]. Here, $\alpha_{e i}$ and $\alpha_{t i}$ were the experimental data and the theoretical predictions, respectively; $N$ was the number of groups of the compared data. The calculated $R^{2}$ values were $0.9963,0.9976,0.9982$, and 0.9988 when thicknesses of the porous metal were $15 \mathrm{~mm}, 20 \mathrm{~mm}, 25 \mathrm{~mm}$, and $30 \mathrm{~mm}$, respectively. It is known that the reliability of the model was proportional to the proximity of the $R^{2}$ values to 1 . The model would be considered reliable when the evaluation index $R^{2}$ was larger than 0.99 . Thus, it could further prove the reliability and practicability of the cuckoo search identification algorithm in another way.

$$
R^{2}=1-\frac{\sum_{i=1}^{N}\left(\alpha_{e i}-\alpha_{t i}\right)^{2}}{\sum_{i=1}^{N} \alpha_{e i}^{2}}
$$




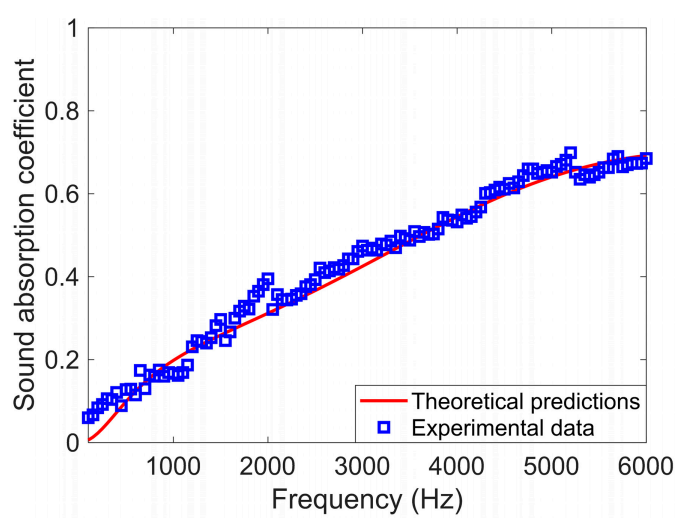

(a)

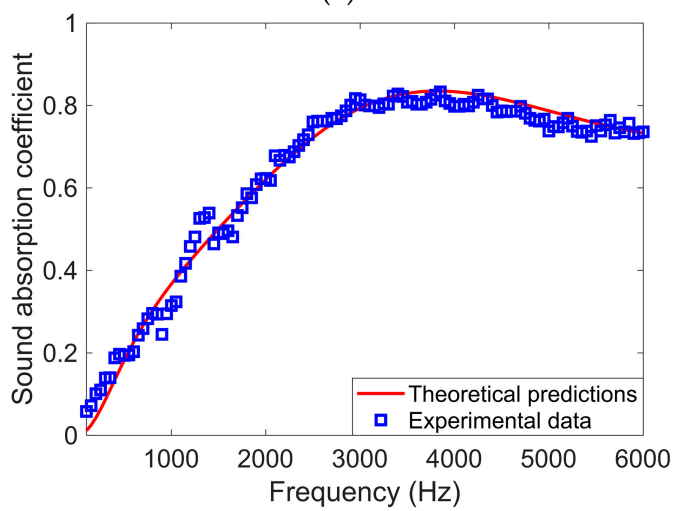

(c)

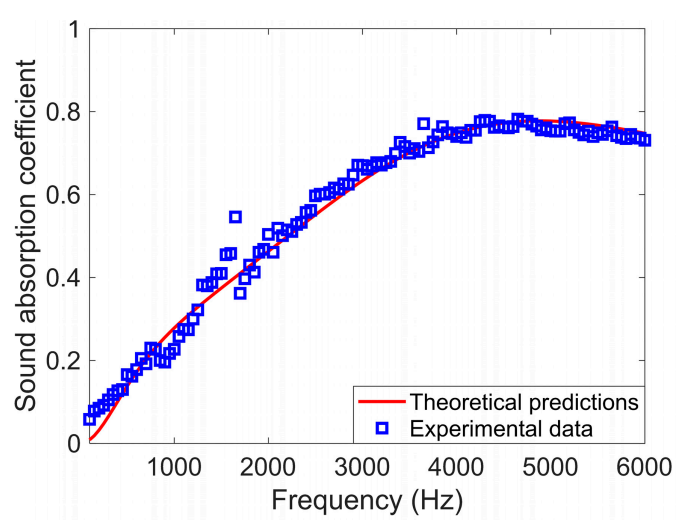

(b)

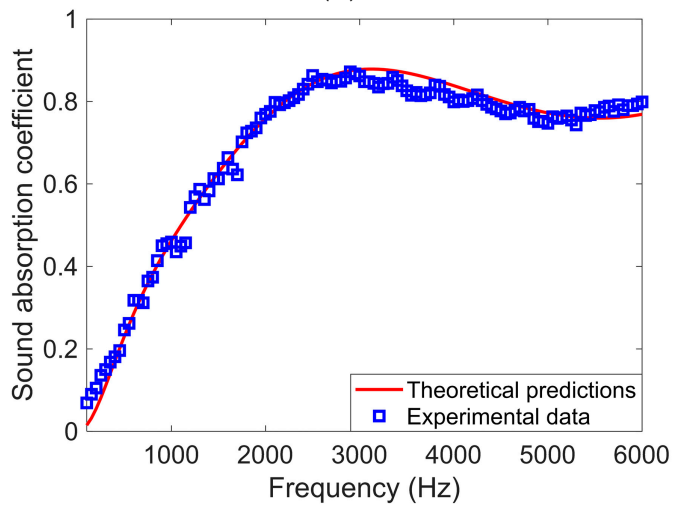

(d)

Figure 6. Comparisons of the theoretical predictions and the experimental data of sound absorption coefficients of the porous metal (a) with a thickness of $15 \mathrm{~mm}$, (b) with a thickness of $20 \mathrm{~mm}$, (c) with a thickness of $25 \mathrm{~mm}$, and (d) with a thickness of $30 \mathrm{~mm}$.

Besides the above experimental verifications, sound absorption coefficients of the porous metal with a thickness of $35 \mathrm{~mm}$ were theoretical analyzed and experimental measured, and the results are shown in Figure 7, which exhibited their consistency. The calculated $R^{2}$ value between the theoretical predictions and the experimental data was 0.9982 , which indicated that the identification of acoustic characteristic parameters of the porous metal through the cuckoo search algorithm had universality other than for the limited thickness. Moreover, the obtained accurate identified acoustic characteristic parameters would be favorable to improve sound absorption coefficients of the porous metal and promote its practical application.

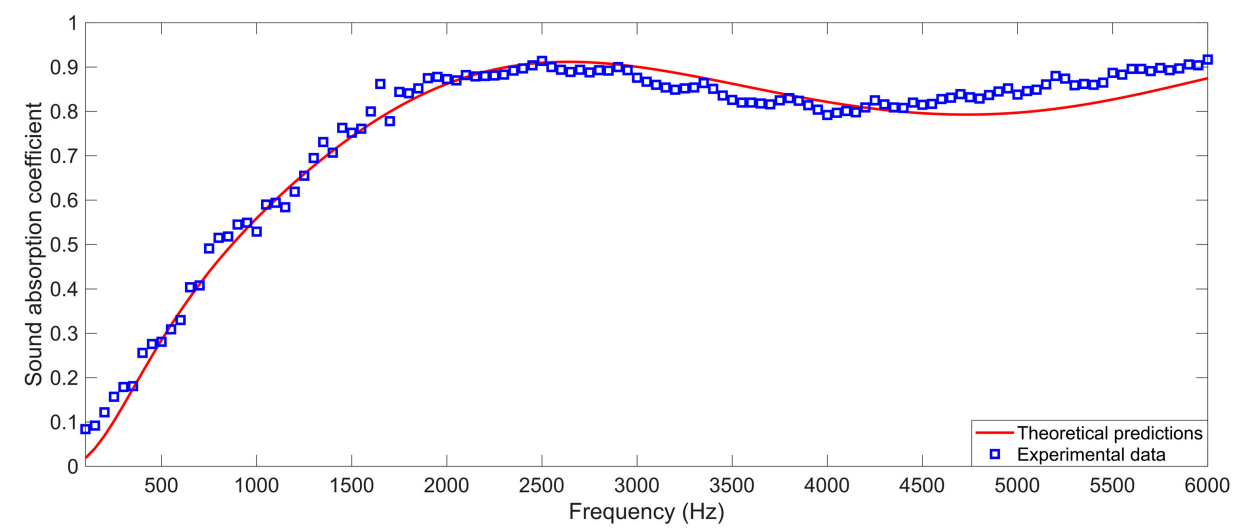

Figure 7. Sound absorption coefficients of the porous metal with a thickness of $35 \mathrm{~mm}$. 


\section{Modeling and Optimization}

The sound absorption coefficient of the porous metal could be improved by a adding microperforated metal panel in front of it to form a composite sound-absorbing structure [13], as shown in Figure 8. Besides the acoustic parameters of the porous metal, structural parameters of the microperforated panel, which included thickness of the panel $t$, diameter of the microhole $d$, and distance between the neighboring holes $b$, together determined the corresponding sound absorption performance of the composite sound-absorbing structure.

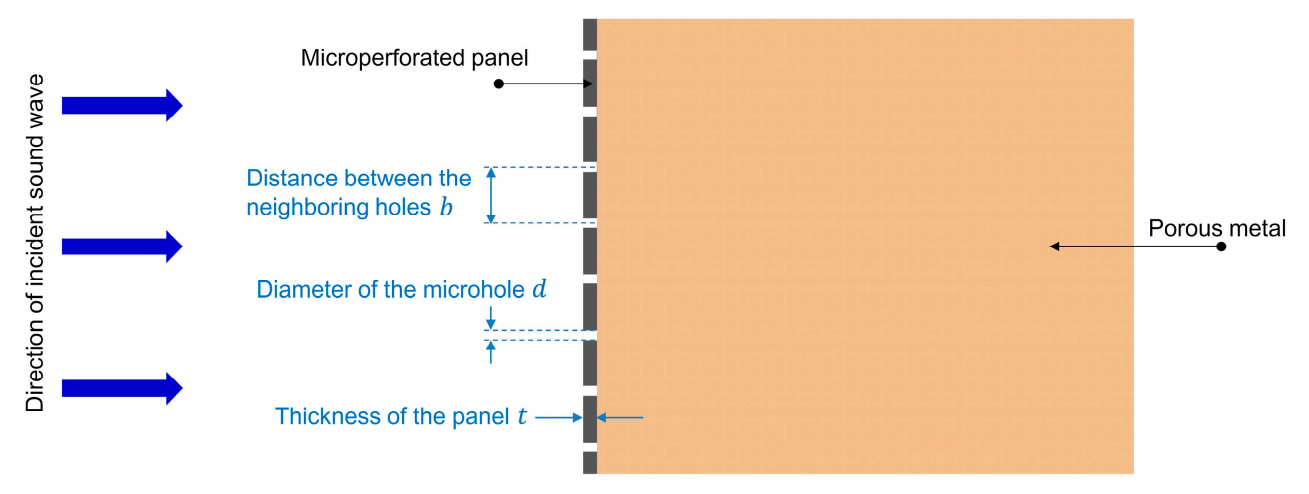

Figure 8. Schematic diagram of the composite sound-absorbing structure.

\subsection{Theoretical Sound Absorption Model}

According to the transfer matrix method [9,13,30-32], the sound absorption coefficient of the composite sound-absorbing structure could be calculated through deriving the transfer matrix of the porous metal and that of the microperforated panel. The transfer matrix of the porous metal $T_{p}$ had already been obtained by Equation (2), and that of the microperforated panel $T_{M}$ could be achieved based on Maa's theory [42-44], as shown in Equation (13). Here, $Z_{s}$ is the acoustic impedance rate of the microperforated metal panel, as shown in Equation (14), which consists of the real part $R$ and imaginary part $X ; j$ is the still symbol of the imaginary number, $j^{2}=-1$.

$$
\begin{gathered}
T_{M}=\left[\begin{array}{cc}
1 & Z_{s} \\
0 & 1
\end{array}\right] \\
Z_{S}=R+j X
\end{gathered}
$$

The real part $R$ and imaginary part $X$ of the acoustic impedance rate can be calculated through Equations (15) and (16), respectively. Here, $\mu$ is the viscosity coefficient of the air with the normal atmospheric temperature, $1.506 \times 10^{-5} \mathrm{~m}^{2} / \mathrm{s}$; $v$ is the temperature conduction coefficient of the metal panel, $2.0 \times 10^{-5} \mathrm{~m}^{2} / \mathrm{s} ; \rho$ is still density of the air, $1.21 \mathrm{~kg} / \mathrm{m}^{3} ; \varepsilon$ is the perforating rate, which can be calculated by Equation (17); $k_{r}$ is the acoustic resistance constant, which can be obtained by Equation (18); $\omega$ is still angular frequency of the sound wave; $k_{m}$ is the acoustic mass constant, which can be achieved by Equation (19) [42-44].

$$
\begin{gathered}
R=\frac{32(\mu+v) \rho}{\varepsilon} \times \frac{t}{d^{2}} \times k_{r} \\
X=\frac{t \omega \rho}{\varepsilon} \times k_{m} \\
\varepsilon=\frac{\pi}{4} \times\left(\frac{d}{b}\right)^{2} \\
k_{r}=\sqrt{1+\frac{k^{2}}{32}}+\frac{\sqrt{2}}{8} \times k \times \frac{d}{t}
\end{gathered}
$$




$$
k_{m}=1+\frac{1}{\sqrt{\left(9+\frac{k^{2}}{2}\right)}}+0.85 \times \frac{d}{t}
$$

In Equations (17)-(19), the symbols $t, d$, and $b$ represent the thickness of the panel, diameter of the microhole, and distance between the neighboring holes, respectively, which are consistent with those in Figure $8 ; k$ is the perforated panel constant, which can be derived by Equation (20). By this method, the transfer matrix of the microperforated panel $T_{M}$ was obtained.

$$
k=\sqrt{\frac{\omega}{\mu+v}} \times \frac{d}{2}
$$

According to the transfer matrix method, the total transfer matrix of the composite sound-absorbing structure $T$ was achieved, as shown in Equation (21). Referring to Equation (1), the sound absorption coefficient of the composite sound-absorbing structure was calculated by Equation (22).

$$
\begin{gathered}
T=\left[\begin{array}{ll}
T_{11} & T_{12} \\
T_{21} & T_{22}
\end{array}\right]=T_{M} \times T_{p} \\
\alpha=\frac{4 \cdot \operatorname{Re}\left(\frac{T_{11}}{T_{21}} \times \frac{1}{\rho c}\right)}{\left[1+\operatorname{Re}\left(\frac{T_{11}}{T_{21}} \times \frac{1}{\rho c}\right)\right]^{2}+\left[\operatorname{Im}\left(\frac{T_{11}}{T_{21}} \times \frac{1}{\rho c}\right)\right]^{2}}
\end{gathered}
$$

\subsection{Parameter Optimization}

Taking the original porous metal with thickness of $20 \mathrm{~mm}$ for example, in order to obtain the maximum improvement of its sound absorption performance, parameters of the utilized prepositive microperforated panel were optimized through cuckoo search algorithm $[8,18,28,29]$, and average sound absorption coefficient of the composite sound-absorbing structure in certain frequency range was treated as the optimization target, as shown in Equation (23). The investigated frequency ranges $\left[f_{\min }, f_{\max }\right]$ in this research were $100-1000 \mathrm{~Hz}, 100-2000 \mathrm{~Hz}, 100-3000 \mathrm{~Hz}, 100-4000 \mathrm{~Hz}, 100-5000 \mathrm{~Hz}$, and $100-6000 \mathrm{~Hz}$, respectively.

$$
\max (\operatorname{average}(\alpha(f))) \quad f \in\left[f_{\min }, f_{\max }\right]
$$

Meanwhile, in order to reduce the influence of the used prepositive microperforated panel to total thickness and weight of the composite sound-absorbing structure, the thickness of the microperforated panel $t$ was set as $0.3 \mathrm{~mm}$. Moreover, according to the definition of the microperforated metal panel [42-44] and taking the manufacturing cost into consideration, the diameter of the hole $d$ and distance between the neighboring holes $b$ (square linear distribution) should not be too small, otherwise the microperforation would be too difficult to realize. Meanwhile, these two parameters should be not too big, otherwise the microperforation would be meaningless. Thus, the constraint conditions for these two parameters were summarized in Equations (24) and (25), respectively. By taking the confirmed optimization target (Equation (23)) and constraint conditions (Equations (24) and (25)) into the cuckoo search algorithm $[8,18,28,29]$, optimal parameters of the microperforated panel for the maximum improvement of sound absorption of the porous metal with different target frequency ranges could be obtained, as shown in the Table 1. For each cuckoo search optimization program, 2000 generations were iterated to find the optimal parameters, and each generation had 1000 groups of solutions, which indicated that a total of two million optional groups of parameters were examined and the obtained optimal parameters were the best among them. Taking a random group of parameters ( $d=0.5 \mathrm{~mm}, b=1.5 \mathrm{~mm}, t=0.3 \mathrm{~mm}$ ), for example, it could be calculated that the corresponding average sound absorption coefficients of the composite structures were $0.1888,0.3751,0.5167,0.5810$, 0.5917 , and 0.5813 when the investigated target frequency ranges were $100-1000 \mathrm{~Hz}, 100-2000 \mathrm{~Hz}$, 
$100-3000 \mathrm{~Hz}, 100-4000 \mathrm{~Hz}, 100-5000 \mathrm{~Hz}$, and 100-6000 Hz, respectively, which could prove that the obtained optimal parameters in the Table 1 was the best option.

$$
\begin{aligned}
& 1 \times 10^{-5} m \leq d \leq 1 \times 10^{-3} m \\
& 1 \times 10^{-5} m \leq b \leq 2 \times 10^{-2} m
\end{aligned}
$$

Table 1. Optimal parameters of the microperforated panel for maximum improvement of sound absorption of the porous metal with different target frequency ranges.

\begin{tabular}{ccccc}
\hline $\begin{array}{c}\text { Frequency Range } \\
\mathbf{( H z )}\end{array}$ & $\begin{array}{c}\text { Thickness of } \\
\text { Panel (mm) }\end{array}$ & $\begin{array}{c}\text { Diameter of } \\
\text { the Hole } \mathbf{( m m )}\end{array}$ & $\begin{array}{c}\text { Distance of the } \\
\text { Neighboring } \\
\text { Holes (mm) }\end{array}$ & $\begin{array}{c}\text { Average Sound } \\
\text { Absorption } \\
\text { Coefficient }\end{array}$ \\
\hline $100-1000$ & 0.3 & 0.79 & 9.61 & 0.5393 \\
$100-2000$ & 0.3 & 0.37 & 2.91 & 0.6533 \\
$100-3000$ & 0.3 & 0.23 & 1.27 & 0.7159 \\
$100-4000$ & 0.3 & 0.15 & 0.58 & 0.7562 \\
$100-5000$ & 0.3 & 0.08 & 0.17 & 0.7830 \\
$100-6000$ & 0.3 & 0.05 & 0.07 & 0.7949 \\
\hline
\end{tabular}

Comparisons of theoretical sound absorption coefficients of the optimized composite sound-absorbing structures and those of the original porous metal with a thickness of $20 \mathrm{~mm}$ are shown in Figure 9. Corresponding optimal average sound absorption coefficients of the composite sound-absorbing structure were $0.5393,0.6533,0.7159,0.7562,0.7830$, and 0.7949 when the target frequency ranges were 100-1000 Hz, 100-2000 Hz, 100-3000 Hz, 100-4000 Hz, 100-5000 Hz, and 100-6000 Hz, respectively. In contrast, it could be calculated that the average sound absorption coefficients of the porous metal with a thickness of $20 \mathrm{~mm}$ were $0.1575,0.2791,0.3804,0.4644,0.5250$, and 0.5626 , respectively, for the variable target frequency ranges, which indicated that they were increased by $240 \%, 131 \%, 85 \%, 61 \%, 48 \%$, and $41 \%$, respectively, by adding the prepositive microperforated metal panel. It could be easily found that the improvements were remarkable, especially when the target frequency range was in the low-frequency band. The major reason for this phenomenon was that the porous metal had the superiority in the absorption of the mid-high-frequency sound and the microperforated panel would be more effective in absorbing the sound in the low-mid-frequency band [22-24,42-44]. Thus, it could be concluded that the sound absorption performance of the porous metal would be improved significantly by adding the thin prepositive microperforated metal panel and optimizing parameters of the composite sound-absorbing structure, which was propitious to promote the application of the porous metal in sound absorption.

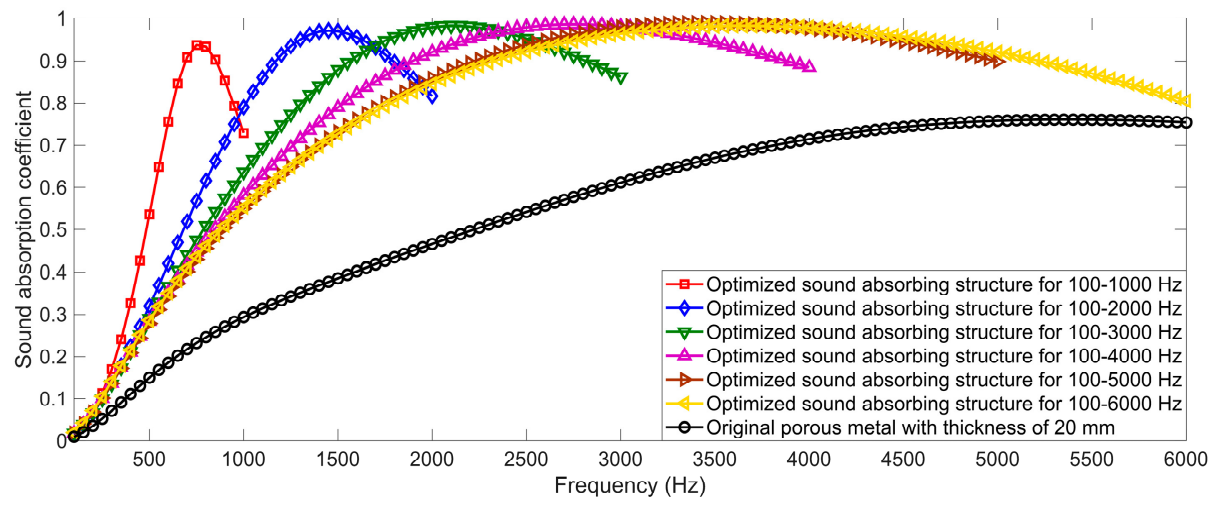

Figure 9. Comparisons of the theoretical sound absorption coefficients of the optimized composite sound-absorbing structures and those of the original porous metal. 


\section{Simulation and Measurement}

In order to validate effectiveness and practicability of the optimal composite sound-absorbing structure, finite element simulation in the virtual acoustic laboratory [33-35] and standing wave tube measurement [36-38] by the AWA6128A detector were conducted successively, which were based on identified acoustic characteristic parameters of the porous metal and optimal parameters of the microperforated panel obtained through the cuckoo search algorithm $[8,18,28,29]$.

\subsection{Finite Element Simulation}

The finite element simulation model of the composite sound-absorbing structure was constructed in the virtual acoustic laboratory [13,33-35], as shown in Figure 10, which could simulate the sound absorption coefficient of the sound absorber according to the standing wave tube method. The size of the rectangular standing wave tube was $60 \mathrm{~mm} \times 60 \mathrm{~mm} \times 300 \mathrm{~mm}$, and the plane wave was introduced at its front surface as an incident wave of the acoustic source. Meanwhile, the tested sound absorber was fixed at the back surface of the tube, and two microphones were installed on the tube. For the porous metal in the composite sound-absorbing structure, its sound absorption effect was confirmed by setting its thickness and inputting the identified acoustic characteristic parameters. Moreover, with regard to the prepositive microperforated panel, its sound absorption effect was represented by the transfer admittance relation loaded between the back surface of the standing wave tube and the front surface of the porous metal, as shown in Figure 10, which could be calculated according to optimal structural parameters in Table 1. The sound absorption coefficients of the composite sound-absorbing structures would be calculated by the obtained sound pressures from the two microphones. By setting the simulated frequency ranges, the sound absorption performance of the composite sound-absorbing structure for the variable target frequency range was simulated, which supplied preliminary verification for the identification and optimization.

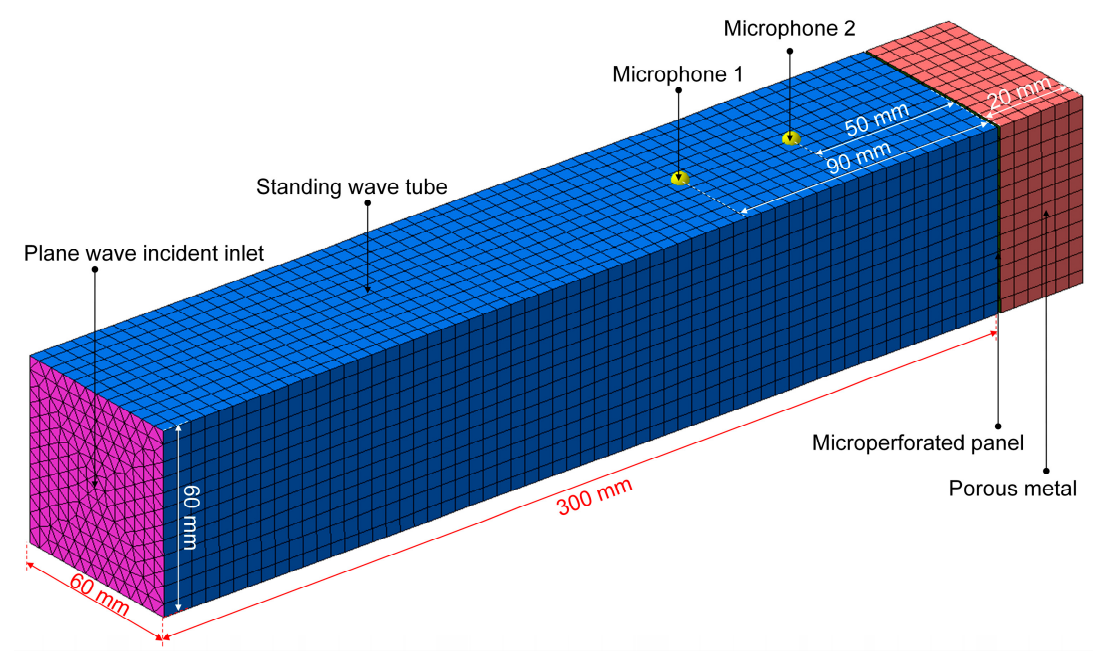

Figure 10. Finite element simulation model of the composite sound-absorbing structure.

\subsection{Experimental Validation}

It could be judged from the optimal parameters in the Table 1 that with increase of frequency ranges $100-1000 \mathrm{~Hz}$ and $100-6000 \mathrm{~Hz}$, diameter of the microhole $d$ and distance between the neighboring holes $b$ gradually decreased, which indicated that the manufacturing cost would rise notably, because there would be more microholes with smaller size to perforate. Taking the optimal composite sound-absorbing structure for the target frequency range of $100-6000 \mathrm{~Hz}$ as an example, the optimal diameter of the hole $d$ was $0.05 \mathrm{~mm}$ and optimal distance between the neighboring holes $b$ was $0.07 \mathrm{~mm}$, which indicated that there would be more than $204(1 / 0.07 \times 1 / 0.07)$ microholes to perforate only for the $1 \mathrm{~mm} \times 1 \mathrm{~mm}$ square area. The excessive manufacturing cost implied that this improvement was meaningless, except 
for some extremely special circumstances. There was a similar situation for the optimal composite sound-absorbing structure with the target frequency range of 100-5000 Hz. Therefore, these two prepositive microperforated panels were not prepared in this study. The other four prepositive microperforated metal panels were prepared through the laser beam machining [45], and the assembled composite sound-absorbing structures are shown in Figure 11. Afterward, sound absorption coefficients of the composite sound-absorbing structures were tested by the AWA6128A detector by replacing the detected porous metal by the composite sound-absorbing structures in Figure 2. According to the operating instruction of the AWA6128A detector, sound absorption coefficients in the frequency range $100-2000 \mathrm{~Hz}$ were obtained through measuring the bigger sample with a diameter of $96 \mathrm{~mm}$, and those in the 2000-6000 Hz range were achieved by testing the smaller sample with a diameter of $30 \mathrm{~mm}$. In this way, actual sound absorption coefficients of the optimal composite sound-absorbing structures for the $100-1000 \mathrm{~Hz}, 100-2000 \mathrm{~Hz}, 100-3000 \mathrm{~Hz}$, and 100-4000 Hz were obtained, which could be compared with theoretical predictions and simulation results. Similar to standing wave tube measurement of the porous metal, each optimal composite sound-absorbing structure was measured 10 times, and the final experimental data was the average value of the 10 testing data, which aimed to reduce the measuring error in the testing program.

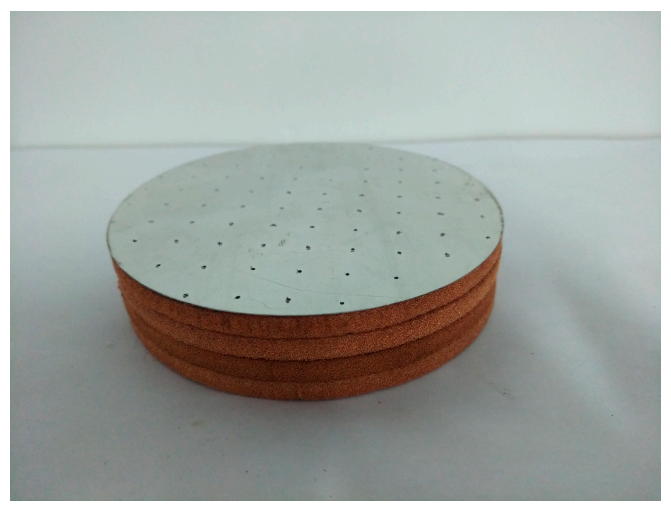

(a)

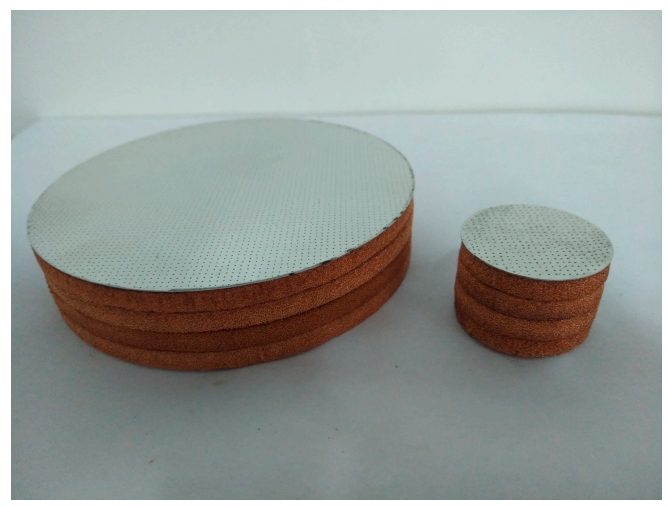

(c)

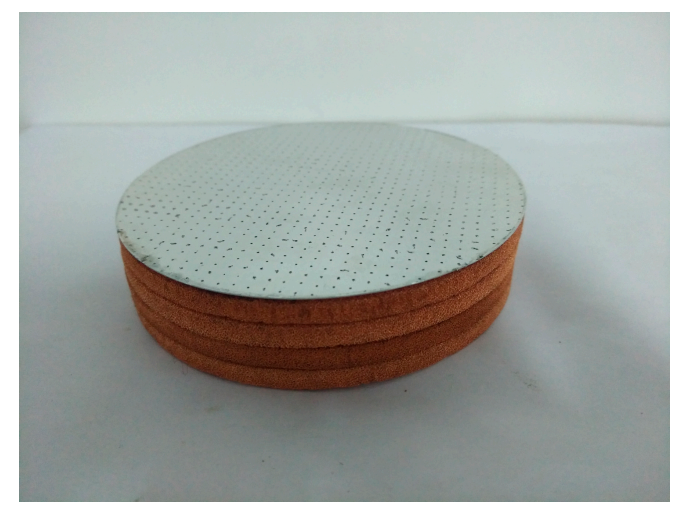

(b)

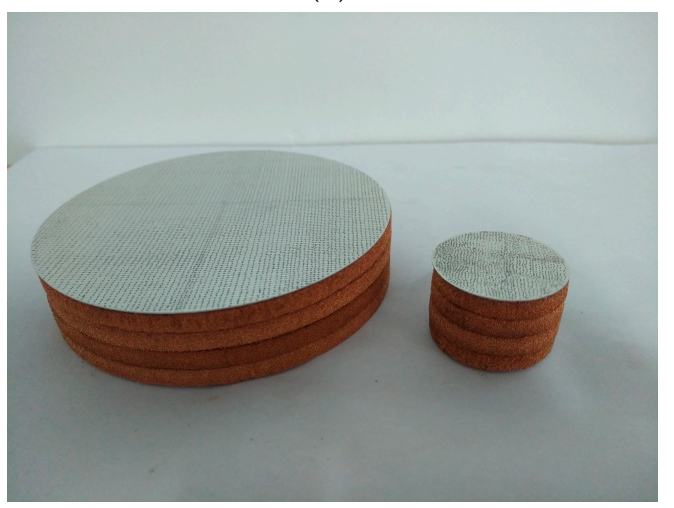

(d)

Figure 11. The composite sound-absorbing structures for improving the sound absorption performance of the porous metal with variable target frequency ranges. (a) Optimal structure for 100-1000 Hz; (b) optimal structure for 100-2000 Hz; (c) optimal structure for 100-3000 Hz; (d) optimal structure for 100-4000 Hz.

\section{Results and Discussions}

Comparisons among the theoretical predictions, simulation results, and experimental data of sound absorption coefficients of the composite sound-absorbing structures with the variable target frequency ranges are shown in Figure 12. It could be observed that the basic evolution trends of data of sound absorption coefficients in theory, those in simulation, and those in the experiment were 
consistent, no matter if the target frequency ranges were $100-1000 \mathrm{~Hz}, 100-2000 \mathrm{~Hz}, 100-3000 \mathrm{~Hz}$, or 100-4000 Hz. Therefore, it could preliminarily prove that the sound absorption performance of the porous metal was effectively improved by adding the prepositive microperforated metal panel and optimizing its structural parameters.

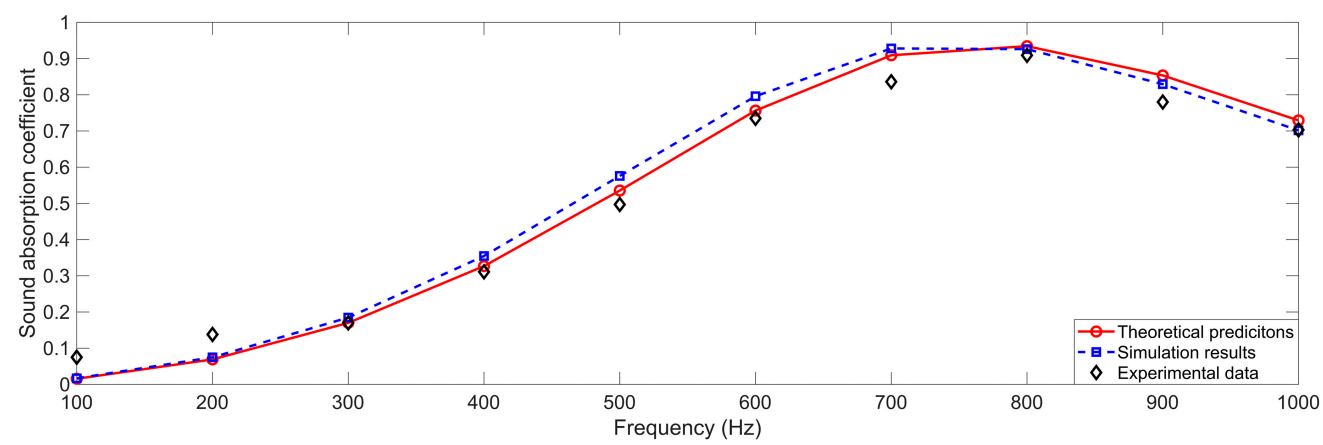

(a)

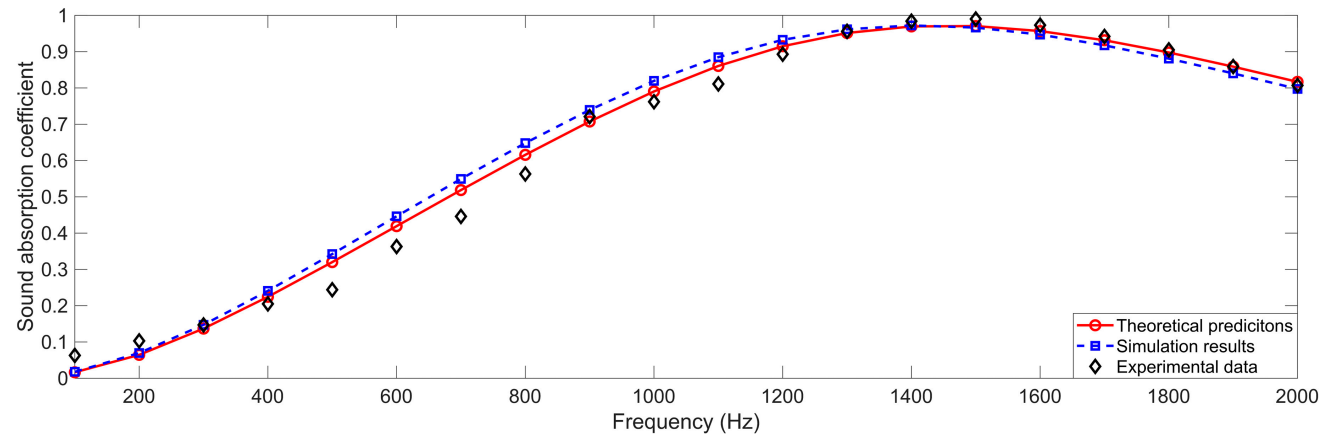

(b)

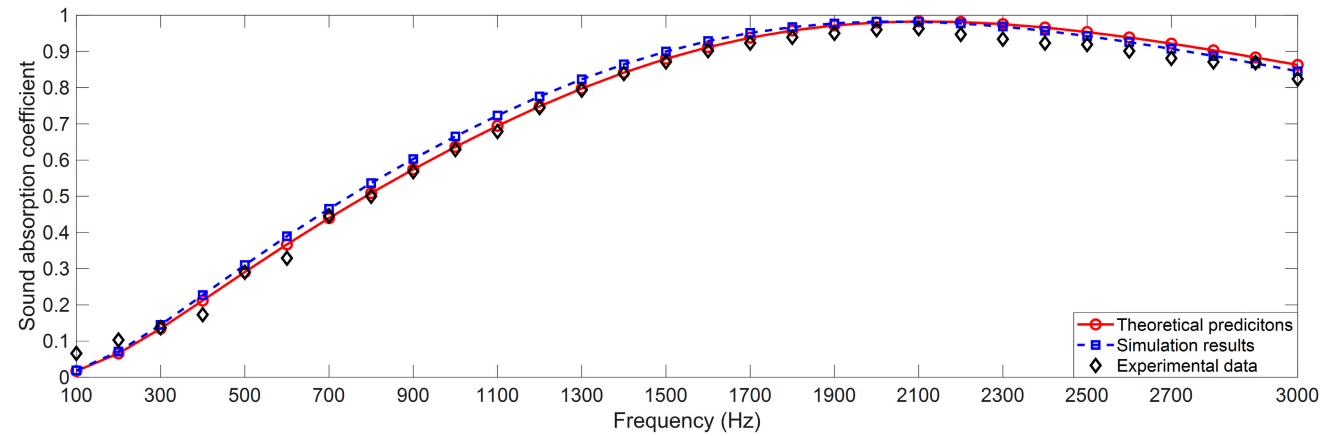

(c)

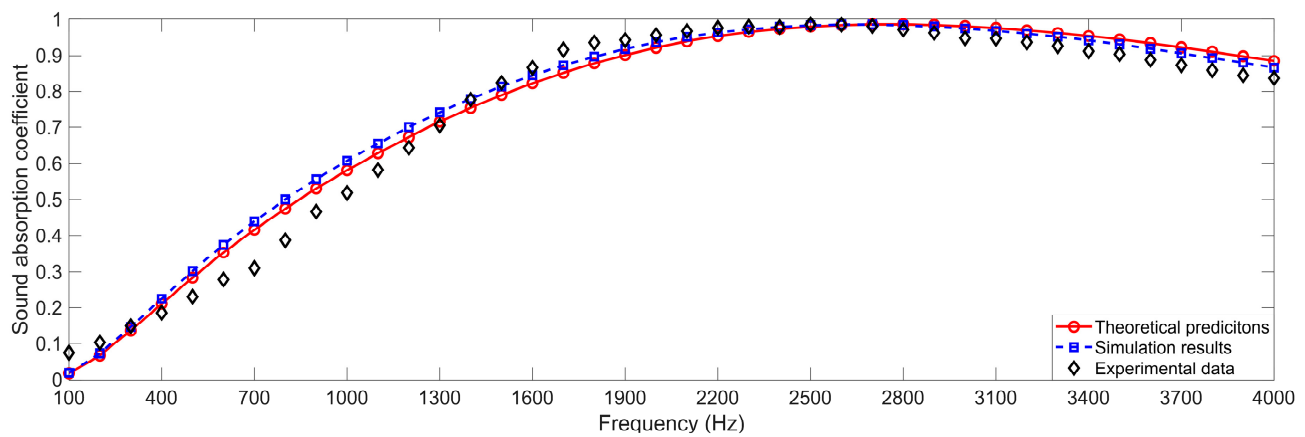

(d)

Figure 12. Comparisons of sound absorption coefficients of the composite sound-absorbing structure with variable target frequency ranges. (a) Optimal structure for 100-1000 Hz; (b) optimal structure for 100-2000 Hz; (c) optimal structure for 100-3000 Hz; (d) optimal structure for 100-4000 Hz. 
Average sound absorption coefficients of the composite sound-absorbing structures with the variable target frequency ranges are summarized in Table 2. It could be found that the deviation among the average sound absorption coefficient in theory, in simulation, and in actual was smaller than 0.05 , which proved the effectiveness and accuracy of the theoretical sound absorption model, cuckoo search optimization algorithm, and finite element simulation method.

Table 2. Average sound absorption coefficients of the composite sound-absorbing structures.

\begin{tabular}{cccc}
\hline \multirow{2}{*}{ Investigated Frequency Range } & \multicolumn{3}{c}{ Average Sound Absorption Coefficient } \\
\cline { 2 - 4 } & in Actual & in Theory & in Simulation \\
\hline $100-1000 \mathrm{~Hz}$ & 0.5393 & 0.5493 & 0.5154 \\
$100-2000 \mathrm{~Hz}$ & 0.6533 & 0.6627 & 0.6369 \\
$100-3000 \mathrm{~Hz}$ & 0.7159 & 0.7195 & 0.6770 \\
$100-4000 \mathrm{~Hz}$ & 0.7562 & 0.7595 & 0.7378 \\
\hline
\end{tabular}

The total departure of the regressive average value $R^{2}$ in Equation (12) was used to express the deviation quantitatively, as shown in Table 3, and the experimental data was treated as the reference. It could be observed that all the total departure of the regressive average value $R^{2}$ was larger than 0.99 , and their average value was 0.9951 , which provided quantitative evidence to excellent consistencies among the theoretical predictions, simulation results, and experimental data. Meanwhile, it could further exhibit reliability and accuracy of the theoretical modeling, parameter optimization, and finite element simulation.

Table 3. Deviations among the theoretical predictions, simulation results, and experimental data.

\begin{tabular}{ccc}
\hline \multirow{2}{*}{ Investigated Frequency Range } & \multicolumn{2}{c}{$\begin{array}{c}\text { Total Departure of the Regressive Average Value Relative to } \\
\text { Experimental Data }\end{array}$} \\
\cline { 2 - 3 } & for Theoretical Predictions & for Simulation Results \\
\hline $100-1000 \mathrm{~Hz}$ & 0.9937 & 0.9914 \\
$100-2000 \mathrm{~Hz}$ & 0.9974 & 0.9949 \\
$100-3000 \mathrm{~Hz}$ & 0.9965 & 0.9943 \\
$100-4000 \mathrm{~Hz}$ & 0.9968 & 0.9964 \\
\hline
\end{tabular}

Comparisons of the actual average sound absorption coefficient of the composite sound-absorbing structures with that of the original porous metal for different target frequency ranges are shown in Table 4. The improvements were $227.24 \%, 128.20 \%, 77.97 \%$, and $58.87 \%$ corresponding to the target frequency ranges of 100-1000 Hz, 100-2000 Hz, 100-3000 Hz, and 100-4000 Hz, respectively. Although the actual improvement was smaller than the corresponding theoretical improvement of $240 \%, 131 \%$, $85 \%$, and $61 \%$, obvious improvement of the sound absorption performance of the porous metal was realized by adding the prepositive microperforated metal panel with a tiny increase in the occupied space (total thickness increased from $20 \mathrm{~mm}$ to $20.3 \mathrm{~mm}$ ) and few addition in the weight. Thus, the proposed method in this study, which consisted of identification of acoustic characteristic parameters and improvement of sound absorption performance, was valuable and practical. 
Table 4. Actual average sound absorption coefficients of the composite sound-absorbing structures and those of the original porous metals.

\begin{tabular}{cccc}
\hline \multirow{2}{*}{$\begin{array}{c}\text { Investigated Frequency } \\
\text { Range }\end{array}$} & \multicolumn{3}{c}{ Actual Average Sound Absorption Coefficients } \\
\cline { 2 - 4 } & for Composite Structure & $\begin{array}{c}\text { for Original Porous } \\
\text { Metal }\end{array}$ & Improvement \\
\hline $100-1000 \mathrm{~Hz}$ & 0.5154 & 0.1575 & $227.24 \%$ \\
$100-2000 \mathrm{~Hz}$ & 0.6369 & 0.2791 & $128.20 \%$ \\
$100-3000 \mathrm{~Hz}$ & 0.6770 & 0.3804 & $77.97 \%$ \\
$100-4000 \mathrm{~Hz}$ & 0.7378 & 0.4644 & $58.87 \%$ \\
\hline
\end{tabular}

\section{Conclusions}

The identification of acoustic characteristic parameters and improvement of the sound absorption performance for the porous metal were conducted in this research. Through the theoretical sound absorption modeling, parameter identification and optimization, finite element simulation analysis, and standing wave tube measurement, the following conclusions were obtained in this study.

(1) Acoustic characteristic parameters of the porous metal were identified through the cuckoo search identification algorithm based on the theoretical sound absorption model and experimental data of its sound absorption coefficients. These identified acoustic characteristic parameters were close to the labeled porosity and static flow resistivity. Meanwhile, through the standing wave tube measurement of sound absorption coefficients of the porous metal with the different thickness, excellent consistencies between the experimental data and theoretical predictions proved the reliability of the cuckoo search algorithm, which provided a foundation for the following improvement.

(2) The sound absorption performance of the porous metal with different target frequency range was improved through adding microperforated metal panel to form a composite sound-absorbing structure, and optimal parameters of the added microperforated metal panel were obtained by the cuckoo search optimization algorithm based on the constructed theoretical model. Average sound absorption coefficients of these optimal composite sound-absorbing structures were $0.5393,0.6533$, $0.7159,0.7562,0.7830$, and 0.7949 when the target frequency ranges were $100-1000 \mathrm{~Hz}, 100-2000 \mathrm{~Hz}$, $100-3000 \mathrm{~Hz}, 100-4000 \mathrm{~Hz}, 100-5000 \mathrm{~Hz}$, and 100-6000 Hz, respectively, which increased by $240 \%$, $131 \%, 85 \%, 61 \%, 48 \%$, and $41 \%$, respectively, relative to the original porous metal with a thickness of $20 \mathrm{~mm}$. The sound absorption performance of the porous metal was significantly improved.

(3) Finite element simulation analysis in the virtual acoustic laboratory and standing wave tube measurement by the AWA6128A detector were conducted to verify the effectiveness and practicability of the optimal composite sound-absorbing structures. Excellent consistencies among the theoretical predictions, simulation results, and experimental data proved the accuracies and effectiveness of the constructed theoretical sound absorption model, the selected cuckoo search identification and optimization algorithm, and the adopted finite element simulation method.

(4) When the target frequency ranges were $100-1000 \mathrm{~Hz}, 100-2000 \mathrm{~Hz}, 100-3000 \mathrm{~Hz}$, and $100-4000 \mathrm{~Hz}$, corresponding actual average sound absorption coefficients of the optimal composite sound-absorbing structures were $0.5154,0.6369,0.6770$, and 0.7378 , respectively, and those of the original porous metal with thickness of $20 \mathrm{~mm}$ were $0.1575,0.2791,0.3804$, and 0.4644 , respectively, which exhibited the obvious improvement of the sound absorption performance with a tiny increase in the occupied space and a small addition in weight. Judging from the actual improvements of $227.24 \%, 128.20 \%, 77.97 \%$, and $58.87 \%$, respectively, it could be concluded that these improvements were more effective for the low-frequency range, which was consistent with common views that the microperforated panel had superiority in the low-to-middle-frequency sound absorption and the porous metal was good at the middle-to-high-frequency period.

In this study, acoustic characteristic parameters of the porous metal were precisely identified and its sound absorption performances were significantly improved, which would be favorable to promote its practical application in the fields of sound absorption and noise reduction. 
Author Contributions: Conceptualization, X.S.; software, X.Z.; validation, X.Y. and X.Z.; formal analysis, X.Y. and H.D.; investigation, Q.Y.; data curation, Q.Y. and X.Y.; writing-original draft preparation, X.Y. and X.S.; writing-review and editing, X.S. and H.D.; supervision, X.S.; funding acquisition, X.S. All authors have read and agreed to the published version of the manuscript.

Funding: This research was funded by the National Natural Science Foundation of China, grant number 51505498; the Natural Science Foundation of Jiangsu Province, grant number BK20150714; the National Key R\&D Program of China, grant number 2016YFC0802900; the Hong Kong Scholars Program, grant number XJ2017025.

Acknowledgments: The authors wish to express their sincere thanks to Hangzhou Aihong Instruments Co., Ltd., China for the support with the AWA6128A detector.

Conflicts of Interest: The authors declare no conflicts of interest.

\section{References}

1. Hakamada, M.; Kuromura, T.; Chen, Y.P.; Kusuda, H.; Manuchi, M. High sound absorption of porous aluminum fabricated by spacer method. Appl. Phys. Lett. 2006, 88, 254106. [CrossRef]

2. Ru, J.M.; Bo, K.; Liu, Y.G.; Wang, X.L.; Fan, T.X.; Zhang, D. Microstructure and sound absorption of porous copper prepared by resin curing and foaming method. Mater. Lett. 2015, 139, 318-321. [CrossRef]

3. Zhai, W.; Yu, X.; Song, X.; Ang, L.Y.L.; Cui, F.S.; Lee, H.P.; Li, T. Microstructure-based experimental and numerical investigations on the sound absorption property of open-cell metallic foams manufactured by a template replication technique. Mater. Des. 2018, 137, 108-116. [CrossRef]

4. Yang, X.C.; Peng, K.; Shen, X.M.; Zhang, X.N.; Bai, P.F.; Xu, P.J. Geometrical and dimensional optimization of sound absorbing porous copper with cavity. Mater. Des. 2017, 131, 297-306. [CrossRef]

5. Liu, P.S.; Qing, H.B.; Hou, H.L. Primary investigation on sound absorption performance of highly porous titanium foams. Mater. Des. 2015, 85, 275-281. [CrossRef]

6. Bai, P.F.; Shen, X.M.; Zhang, X.N.; Yang, X.C.; Yin, Q.; Liu, A.X. Influences of compression ratio on sound absorption performance of porous nickel-iron alloy. Metals 2018, 8, 539. [CrossRef]

7. Bai, P.F.; Yang, X.C.; Shen, X.M.; Zhang, X.N.; Li, Z.Z.; Yin, Q.; Jiang, G.L.; Yang, F. Sound absorption performance of the acoustic absorber fabricated by compression and microperforation of the porous metal. Mater. Des. 2019, 167, 107637. [CrossRef]

8. Yang, X.C.; Shen, X.M.; Bai, P.F.; He, X.H.; Zhang, X.N.; Li, Z.Z.; Chen, L.; Yin, Q. Preparation and characterization of gradient compressed porous metal for high-efficiency and thin-thickness acoustic absorber. Materials 2019, 12, 1413. [CrossRef]

9. Shen, X.M.; Bai, P.F.; Chen, L.; To, S.; Yang, F.; Zhang, X.N.; Yin, Q. Development of thin sound absorber by parameter optimization of multilayer compressed porous metal with rear cavity. Appl. Acoust. 2020, 159, 107071. [CrossRef]

10. Otaru, A.J.; Morvan, H.P.; Kennedy, A.R. Modelling and optimisation of sound absorption in replicated microcellular metals. Scr. Mater. 2018, 150, 152-155. [CrossRef]

11. Lu, M.; Meng, B.N.; Liu, P.S.; Xu, X.B. Effect of perforated panel combination on sound absorption performance of nickel foam. Rare Metal Mater. Eng. 2015, 44, 3083-3088.

12. Peng, P.; Wang, K.S.; Wang, W.; Huang, L.Y.; Qiao, K.; Che, Q.Y.; Xi, X.P.; Zhang, B.; Cai, J. High-performance aluminium foam sandwich prepared through friction stir welding. Mater. Lett. 2019, 236, 295-298. [CrossRef]

13. Shen, X.M.; Bai, P.F.; Yang, X.C.; Zhang, X.N.; To, S. Low-frequency sound absorption by optimal combination structure of porous metal and microperforated panel. Appl. Sci. 2019, 9, 1507. [CrossRef]

14. Chevillotte, F.; Perrot, C.; Panneton, R. Microstructure based model for sound absorption predictions of perforated closed-cell metallic foams. J. Acoust. Soc. Am. 2010, 128, 1766-1776. [CrossRef] [PubMed]

15. Perrot, C.; Chevillotte, F.; Panneton, R. Bottom-up approach for microstructure optimization of sound absorbing materials. J. Acoust. Soc. Am. 2008, 124, 940-948. [CrossRef] [PubMed]

16. Zhao, W.C.; Zheng, C.J.; Chen, H. Acoustic topology optimization of porous material distribution based on an adjoint variable FMBEM sensitivity analysis. Eng. Anal. Bound. Elem. 2019, 99, 60-75. [CrossRef]

17. Zhu, J.L.; Sun, J.; Tang, H.P.; Wang, J.Z.; Ao, Q.B.; Bao, T.F.; Song, W.D. Gradient-structural optimization of metal fiber porous materials for sound absorption. Powder Technol. 2016, 301, 1235-1241. [CrossRef]

18. Yang, F.; Shen, X.M.; Bai, P.F.; Zhang, X.N.; Li, Z.Z.; Yin, Q. Optimization and Validation of Sound Absorption Performance of 10-Layer Gradient Compressed Porous Metal. Metals 2019, 9, 588. [CrossRef] 
19. Takezawa, A.; Yamamoto, T.; Zhang, X.P.; Yamakawa, K.; Nakano, S.; Kitamura, M. An objective function for the topology optimization of sound-absorbing materials. J. Sound Vib. 2019, 443, 804-819. [CrossRef]

20. Barbosa, L.R.; Lenzi, A. Parametric optimization and analysis of metallic porous material used for discharge system of hermetic compressor. Appl. Acoust. 2018, 136, 94-101. [CrossRef]

21. Park, J.H.; Yang, S.H.; Lee, H.R.; Yu, C.B.; Pak, S.Y.; Oh, C.S.; Kang, Y.J.; Youn, J.R. Optimization of low frequency sound absorption by cell size control and multiscale poroacoustics modeling. J. Sound Vib. 2017, 397, 17-30. [CrossRef]

22. Allard, J.F.; Champoux, Y. New empirical equations for sound propagation in rigid frame fibrous materials. J. Acoust. Soc. Am. 1992, 91, 3346-3353. [CrossRef]

23. Kino, N. Further investigations of empirical improvements to the Johnson-Champoux-Allard model. Appl. Acoust. 2015, 96, 153-170. [CrossRef]

24. Yang, X.C.; Bai, P.F.; Shen, X.M.; Zhang, X.N.; Zhu, J.W.; Yin, Q.; Peng, K. Theoretical modeling and experimental validation of sound absorbing coefficient of porous iron. J. Porous Media 2019, 22, 225-241. [CrossRef]

25. Tao, J.C.; Wang, P.; Qiu, X.J.; Pan, J. Static flow resistivity measurements based on the ISO 10534.2 standard impedance tube. Build. Environ. 2015, 94, 853-858. [CrossRef]

26. Peng, F.; Chang, B.J.; Sun, Y. Nonlinear estimation of static flow resistivity of porous sound absorbing materials. J. Beijing Univ. Technol. 2012, 38, 1756-1760.

27. Sadouki, M.; Fellah, Z.E.A.; Berbiche, A.; Fellah, M.; Mitri, F.G.; Ogam, E.; Depollier, C. Measuring static viscous permeability of porous absorbing materials. J. Acoust. Soc. Am. 2014, 135, 3163-3171. [CrossRef]

28. Yang, X.S.; Deb, S. Engineering Optimisation by Cuckoo Search. Int. J. Math. Model. Numer. Optim. 2010, 1, 330-343. [CrossRef]

29. Yang, X.S.; Deb, S. Cuckoo search: Recent advances and applications. Neural Comput. Appl. 2014, 24, 169-174. [CrossRef]

30. Verdière, K.; Panneton, R.; Elkoun, S.; Dupont, T.; Leclaire, P. Transfer matrix method applied to the parallel assembly of sound absorbing materials. J. Acoust. Soc. Am. 2013, 134, 4648-4658. [CrossRef]

31. Yang, X.C.; Bai, P.F.; Shen, X.M.; To, S.; Chen, L.; Zhang, X.N.; Yin, Q. Optimal design and experimental validation of sound absorbing multilayer microperforated panel with constraint conditions. Appl. Acoust. 2019, 146, 334-344. [CrossRef]

32. Lee, D.H.; Kwon, Y.P. Estimation of the absorption performance of multiple layer perforated panel systems by transfer matrix method. J. Sound Vib. 2004, 278, 847-860. [CrossRef]

33. Gaudreau, M.-A.; Sgard, F.; Laville, F.; Nélisse, H. A finite element model to improve noise reduction based attenuation measurement of earmuffs in a directional sound field. Appl. Acoust. 2017, 119, 66-77. [CrossRef]

34. Yang, X.C.; Chen, L.; Shen, X.M.; Bai, P.F.; To, S.; Zhang, X.N.; Li, Z.Z. Optimization of geometric parameters of the standardized multilayer microperforated panel with finite dimension. Noise Control Eng. J. 2019, 67, 197-209. [CrossRef]

35. Carillo, K.; Sgard, F.; Doutres, O. Numerical study of the broadband vibro-acoustic response of an earmuff. Appl. Acoust. 2018, 134, 25-33. [CrossRef]

36. Bujoreanu, C.; Nedeff, F.; Benchea, M.; Agop, M. Experimental and theoretical considerations on sound absorption performance of waste materials including the effect of backing plates. Appl. Acoust. 2017, 119, 88-93. [CrossRef]

37. Zhao, X.D.; Fan, X.Q. Enhancing low frequency sound absorption of micro-perforated panel absorbers by using mechanical impedance plates. Appl. Acoust. 2015, 88, 123-128. [CrossRef]

38. Emanov, A.F.; Krasnikov, A.A. Use of the standing wave method to study seismically insulated buildings. Seism. Instrum. 2016, 52, 323-349. [CrossRef]

39. Duan, H.Q.; Shen, X.M.; Yang, F.; Bai, P.F.; Lou, X.F.; Li, Z.Z. Parameter Optimization for Composite Structures of Microperforated Panel and Porous Metal for Optimal Sound Absorption Performance. Appl. Sci. 2019, 9, 4798. [CrossRef]

40. Anovitz, L.M.; Cole, D.R. Characterization and analysis of porosity and pore structures. Rev. Mineral. Geochem. 2015, 80, 61-164. [CrossRef]

41. Peng, Z.H.; Xin, H.M. The reflexive least squares solutions of the general coupled matrix equations with a submatrix constraint. Appl. Math. Comput. 2013, 225, 425-445. [CrossRef] 
42. Maa, D.Y. Theory and design of microperforated panel sound-absorbing constructions. Sci. Sin. 1975, 18, $55-71$.

43. Maa, D.Y. Design of microperforated panel constructions. Acta Acust. 1988, 13, 174-180.

44. Maa, D.Y. Potential of microperforated panel absorber. J. Acoust. Soc. Am. 1998, 104, 2861-2866. [CrossRef]

45. Qian, Y.J.; Kong, D.Y.; Fei, J.T. A note on the fabrication methods of flexible ultra microperforated panels. Appl. Acoust. 2015, 90, 138-142. [CrossRef]

(C) 2020 by the authors. Licensee MDPI, Basel, Switzerland. This article is an open access article distributed under the terms and conditions of the Creative Commons Attribution (CC BY) license (http://creativecommons.org/licenses/by/4.0/). 